\title{
Multifractal characteristics of shale and tight sandstone pore structures with nitrogen adsorption and nuclear magnetic resonance
}

\author{
Fu-Yong Wang ${ }^{1} \cdot$ Kun Yang ${ }^{1} \cdot$ Yun Zai ${ }^{1}$
}

Received: 13 November 2019 / Published online: 16 August 2020

(c) The Author(s) 2020

\begin{abstract}
Based on the experiments of nitrogen gas adsorption $\left(\mathrm{N}_{2} \mathrm{GA}\right)$ and nuclear magnetic resonance (NMR), the multifractal characteristics of pore structures in shale and tight sandstone from the Chang 7 member of Triassic Yanchang Formation in Ordos Basin, NW China, are investigated. The multifractal spectra obtained from $\mathrm{N}_{2} \mathrm{GA}$ and NMR are analyzed with pore throat structure parameters. The results show that the pore size distributions obtained from $\mathrm{N}_{2} \mathrm{GA}$ and NMR are different, and the obtained multifractal characteristics vary from each other. The specific surface and total pore volume obtained by $\mathrm{N}_{2} \mathrm{GA}$ experiment have correlations with multifractal characteristics. For the core samples with the similar specific surface, the value of the deviation of multifractal spectra $R_{d}$ increases with the increase in the proportion of large pores. When the proportion of macropores is small, the $R_{d}$ value will increase with the increase in specific surface. The multifractal characteristics of pore structures are influenced by specific surface area, average pore size and adsorption volume measured from $\mathrm{N}_{2} \mathrm{GA}$ experiment. The multifractal characteristic parameters of tight sandstone measured from NMR spectra are larger than those of shale, which may be caused by the differences in pore size distribution and porosity of shale and tight sandstone.
\end{abstract}

Keywords Shale $\cdot$ Tight sandstone $\cdot$ Nitrogen adsorption $\cdot$ Nuclear magnetic resonance $\cdot$ Multifractal $\cdot$ Pore structure

\section{List of symbols}

$D_{q} \quad$ Generalized fractal dimension

$D_{1} \quad$ The generalized fractal dimension when $q=1$

$f(\alpha) \quad$ Multifractal spectra

$f(\alpha)$ max The maximum values of $f(\alpha)$

$f(\alpha)_{\min }$ The minimum values of $f(\alpha)$

$\boldsymbol{k} \quad$ Positive integer

$N(\varepsilon) \quad$ The number of sections divided

$N_{\alpha}(\varepsilon) \quad$ The number of boxes with singularity index between $\alpha$ and $\alpha+d \alpha$

$P_{i}(\varepsilon) \quad$ Probability distribution function

$\boldsymbol{q} \quad$ Exponent

$R_{\mathrm{d}} \quad$ Deviation of the multifractal spectra

$\alpha \quad$ Singularity index

$\alpha_{0}(q) \quad$ Singularity index corresponding to $f(\alpha)_{\max }$

$\alpha\left(q^{+}\right) \quad$ The smallest value of $\alpha_{0}(q)$ when $q>0$

Edited by Jie Hao and Xiu-Qiu Peng

Fu-Yong Wang

wangfuyong@cup.edu.cn

1 Unconventional Petroleum Research Institute, China University of Petroleum (Beijing),

Changping, Beijing 102249, China $\alpha\left(q^{-}\right) \quad$ The largest value of $\alpha_{0}(q)$ when $q<0$

$\alpha_{1}(q) \quad$ Width to the left of the multifractal spectra

$\alpha_{2}(q) \quad$ Width to the right of the multifractal spectra

$\Delta \alpha(q) \quad$ The width of the multifractal spectra

$\chi(q, \varepsilon) \quad$ Partition function

$\varepsilon \quad$ The scale of box

$\mu_{i}(\varepsilon) \quad$ The pore volume for the $i$ th interval

$\tau(q) \quad$ Mass exponent

\section{Introduction}

Shale oil resources are abundant in China and it is another hot spot in current exploration and development (Hu et al. 2017). The Chang 7 member of the Yanchang Formation in the Ordos Basin of China is rich in unconventional petroleum resources. In particular, the exploration and development of shale oil in Ordos Basin has made important progress (Yang et al. 2016, 2019a, b). The Chang 7 member has the characteristics of continuous development of organic shale and sandstone, and therefore studying the pore structure characteristics of shale and tight sandstone is of great significance for the effective development of the Chang 7 
shale oil resources in the Yanchang Formation of the Ordos Basin, China (Er et al. 2016; Yin et al. 2020).

At present, there are several experimental methods for characterizing shale and tight sandstone pore structures, including thin section analysis, scanning electron microscopy (SEM), high-pressure mercury intrusion (HPMI) (Lai et al. 2018; Wang et al. 2019), $\mathrm{N}_{2} \mathrm{GA}$ (Chen et al. 2017; Li et al. 2019; Singh 2016; Singh and Cai 2018), NMR (Shao et al. 2017; Zhao et al. 2020), micro/nano CT scanning (Peng et al. 2011; Yang et al. 2019) and so on. In 1980s Mandelbrot proposed the fractal theory and then it has been widely used in many fields (Mandelbrot 1983), and many scholars have studied the characteristics of pore structures in sedimentary rocks combining fractal theory with various experimental methods ( $\mathrm{Li}$ et al. 2017; Wang et al. 2018). For example, Lai et al. (2016) used HPMI and NMR to study the pore structures of tight sandstone, and found that micropores play an important role in the heterogeneity of reservoir rocks and they can be quantitatively characterized by fractal dimension.

As the one of the main tight oil/gas reservoirs in China, the pore structures of tight sandstones in the Ordos Basin have been widely reported (Du and Shi 2019; Li et al. 2016; Wang et al. 2020). The results show that the fractal dimension can effectively characterize the complexity of the pore structure, and the pore structure complexity and heterogeneity increase with the increase in fractal dimension (Wang et al. 2018; Lyu et al. 2017). Li et al. (2017) studied the pore structures of Chang 7 tight sandstones using HPMI combined with fractal theory, and the value of calculated fractal dimensions changes from 2.2520 to 2.7875 . Ju et al. (2019) studied the pore structure and fractal characteristics of Chang 7 shale were combined with $\mathrm{N}_{2} \mathrm{GA}$, and found that the fractal dimensions increase with the increase in organic matter and clay mineral content.

Although the fractal dimension can well represent the complexity of core pore structure, as the pores are not continuously distributed, the single value of the fractal dimension cannot comprehensively characterize the whole pore size distribution. As an extension of the fractal dimension, the multifractal dimension can get the whole properties and local information by analyzing the fluctuation of its probability density (Ferreiro et al. 2010; Liu and Ostadhassan 2019; Liu et al. 2018; Posadas et al. 2009; Xie et al. 2010; Yu et al. 2018; Zhu et al. 2014). Jouini et al. (2011) studied the multifractal characteristics of carbonate rocks based on SEM, and the influence of image magnification on the multifractal characteristics of pore structures was analyzed. Ge et al. (2015) found that the multifractal characteristic parameters of NMR spectra of fine sandstone has strong correlations with the values of $T_{2 \text { cutoff }}$, and the formula for predicting $T_{2 \text { cutoff }}$ based on multifractal parameters was developed. Jiang et al. (2018) studied multifractal characteristics of tight sandstone pore structures with mercury intrusion experiments, and found that the multifractal characteristics have a good correlation with tight sandstone permeability and porosity. Liu et al. (2018) used the NMR $T_{2}$ spectra to analyze the multifractal characteristics of tight sandstone pore structures, and found that the multifractal characteristics of different types of tight sandstones are different and the obtained multifractal parameters can be used for characterize the heterogeneity of pore structures.

In this paper, the multifractal characteristics of the pore structures of shale and tight sandstone core samples from the same exploration well located in the Chang 7 Member of the Ordos Basin are studied based on $\mathrm{N}_{2} \mathrm{GA}$ and NMR experiments. The correlations between multifractal parameters and pore structure parameters of shales and tight sandstones are revealed. Meanwhile, the differences of multifractal characteristics of shales and tight sandstones obtained from $\mathrm{N}_{2} \mathrm{GA}$ and NMR are compared and discussed.

\section{Multifractal theory}

To obtain the multifractal characteristic of pore structures, the intervals of pore size are equally divided into the intervals with the length of $\varepsilon$, and $\varepsilon=L \times 2^{-k}$, where $L$ is the overall range of pore size and $k$ is a positive integer. Therefore, when the scale is $\varepsilon$, the number of sections divided is $2^{k}$, i.e., $N(\varepsilon)=2^{k}$. Therefore, the probability of each interval can be expressed as (Ferreiro et al. 2009):

$P_{i}(\varepsilon)=\frac{\mu_{i}(\varepsilon)}{\sum_{i=1}^{N(\varepsilon)} \mu_{i}(\varepsilon)}$

where $\mu_{i}(\varepsilon)$ is the pore volume for the $i$ th interval. When NMR spectra are used to calculate the multifractal parameters, $\mu_{i}(\varepsilon)$ is the incremental saturation for the $i$ th interval of $\mathrm{T}_{2}$. For the $\mathrm{N}_{2} \mathrm{GA}$ test, $\mu_{i}(\varepsilon)$ is the pore volume of adsorbed nitrogen for the $i$ th interval of relative pressure.

According to the multifractal theory, the probability distribution function $P_{i}(\varepsilon)$ is in a power exponential relationship with the scale $\varepsilon$ (Vázquez et al. 2008):

$P_{i}(\varepsilon) \propto \varepsilon^{\alpha_{i}}$

where $\alpha_{i}$ is the singularity index or named as the coarse Holder exponent.

The number of boxes with singularity index between $\alpha$ and $\alpha+\mathrm{d} \alpha$ is $N_{\alpha}(\varepsilon)$, which also has a power exponential relationship with the scale $\varepsilon$ (Vázquez et al. 2008):

$N_{\alpha}(\varepsilon) \propto \varepsilon^{-f(\alpha)}$

where $f(\alpha)$ is the multifractal spectra, representing the exponential relationship between the similar singularity index and the number of boxes. 
There are many methods of calculating multifractal spectra (Lopes and Betrouni 2009), such as the direct method and the indirect method (the Legendre transformation). The principles of these two different methods are briefly introduced as follows.

\subsection{Direct calculation method}

In 1989, Chhabra and Jensen proposed a direct method to calculate multifractal spectrum, which has been widely used (Chhabra and Roderick 1989; Cuevas 2003). The value of $f(\alpha)$ and $\alpha$ can be calculated with the following formula

$\alpha=\lim _{\varepsilon \rightarrow 0} \frac{\sum_{i=1}^{N(\varepsilon)} I_{i}(q, \varepsilon) \times \log P_{i}(\varepsilon)}{\log (\varepsilon)}$

$f(\alpha)=\lim _{\varepsilon \rightarrow 0} \frac{\sum_{i=1}^{N(\varepsilon)} I_{i}(q, \varepsilon) \times \log I_{i}(\varepsilon)}{\log (\varepsilon)}$

where the parameter $I_{i}(q, \varepsilon)$ is defined as:

$I_{i}(q, \varepsilon)=\frac{P_{i}(\varepsilon)^{q}}{\sum_{i=1}^{N(\varepsilon)} P_{i}(\varepsilon)^{q}}$

where $q$ is an exponent with a range of $[-10,10]$.

\subsection{Indirect calculation method}

The indirect calculation method uses the relationship between the generalized fractal dimension $D_{q}$ and the exponent $q$ to determine the multifractal characteristic, and then the fractal dimension spectra can be calculated (Falconer 2004; Meakin 1990). The generalized fractal dimension can be calculated by its definition (Rényi 1955):

$D_{q}=\frac{1}{q-1} \lim _{\delta \rightarrow 0} \frac{\ln \chi(q, \varepsilon)}{\ln \varepsilon}(q \neq 1)$

where $\chi(q, \varepsilon)$ is a partition function, which is defined as:

$\chi(q, \varepsilon)=\sum_{i=1}^{N(\varepsilon)} P_{i}^{q}(\varepsilon) \propto \varepsilon^{\tau(q)}$

when $q=1$, the following formula can be used for calculating the generalized fractal dimension $D_{1}$, which is also called the information dimension:

$D_{1}=\lim _{\varepsilon \rightarrow 0} \frac{\sum_{i=1}^{N(\varepsilon)} P_{i}(\varepsilon) \log P_{i}^{q}(\varepsilon)}{\log (\varepsilon)}$

$\tau(q)$ is the mass exponent and it can be processed by the following equation: $\tau(q)=\lim _{\varepsilon \rightarrow 0} \frac{\log \chi(q, \varepsilon)}{\log \varepsilon}$

Then combine Eq. (7) and Eq. (10), $D_{q}$ can be simplified as(Halsey et al. 1986):

$D_{q}=\frac{\tau(q)}{q-1}$

Through the Legendre transformation (Halsey et al. 1986), the following equation can be derived as:

$\alpha(q)=\frac{d \tau(q)}{d q}$

$f(\alpha)=q \alpha(q)-\tau(q)$

Previous studies have found that the direct method can calculate the multifractal spectrum more simply and there may be some mistakes in the calculation of multifractal spectrum using Legendre transformation (Halsey et al. 1986). Comparing the two methods mentioned above, it can be found that the generalized fractal dimension and mass exponent can be obtained using the indirect calculation method, which can be used to judge whether the core pore space has multifractal features. Therefore, the direct calculation method is used to obtain the multifractal spectrum and the indirect calculation method is used to compute the generalized fractal dimension and mass exponent in this study.

To characterize the multifractal spectra, the parameters of $\Delta \alpha(q), f(\alpha)_{\max }, f(\alpha)_{\min }, \alpha_{0}(q), \alpha_{1}(q), \alpha_{2}(q), R_{d}$ and $\Delta \alpha(q)$ are defined as Eqs. (14-17). (Ferreiro et al. 2009, 2010). $\Delta \alpha(q)$ is the difference between the maximum and the minimum values of $\alpha(q)$, representing the width of the multifractal spectra and indicating the complexity of the spatial distribution of the pores. The larger the value of $\Delta \alpha(q)$ is, the larger the internal difference and more uneven distribution of pore space will be. $f(\alpha)_{\max }$ and $f(\alpha)_{\min }$ are the maximum and minimum values of $f(\alpha)$, respectively. $\alpha_{0}(q)$ is the singularity index corresponding to $f(\alpha)_{\max }$, and the large value of $\alpha_{0}(q)$ indicates the high heterogeneity of pore volume distribution.

$\alpha_{1}(q)=\alpha_{0}(q)-\alpha\left(q^{+}\right)$

$\alpha_{2}(q)=\alpha\left(q^{-}\right)-\alpha_{0}(q)$

$R_{d}=\alpha_{1}(q)-\alpha_{2}(q)$

$\Delta \alpha(q)=\alpha_{1}(q)+\alpha_{2}(q)$

with $\alpha_{0}(q)$ as the boundary, $\alpha_{1}(q)$ is the width to the left of the multifractal spectra, and $\alpha\left(q^{+}\right)$is the smallest value of $\alpha(q)$ when $q>0 ; \alpha_{2}(q)$ is the width of the right side of 
the multifractal spectra, and $\alpha\left(q^{-}\right)$is the largest value when $q<0 . R_{d}$ indicates the deviation of the multifractal spectra. $R_{d}>0$ indicates the spectra are to the left, and the highvalue information has a great influence on the graphics. $R_{d}<0$ means the spectra are right-skewed, and the lowvalue information has a great influence on graphics. When $R_{d}=0$, the graph is symmetric, and the pore structure tends to be a single fractal characteristic.

\section{Experiments}

All the core samples were collected from the same exploration well of a shale oil reservoir from the Chang 7 Member of the Triassic Yanchang Formation in the Ordos Basin, NW China. The formation depth is a little more than 2000 meters and the lithology of core samples are mostly shale but several sandstone core samples also can be identified. $\mathrm{N}_{2} \mathrm{GA}$ and NMR experiments were conducted to reveal the pore structures of shales and tight sandstones.

\section{1 $\mathrm{N}_{2} \mathrm{GA}$}

10 shale core plugs and 3 sandstone core plugs were selected for $\mathrm{N}_{2} \mathrm{GA}$ tests ( $\mathrm{Li}$ et al. 2019). The following is a brief introduction of the principle of $\mathrm{N}_{2} \mathrm{GA}$. When the temperature is constant, as the relative pressure increases, the amount of nitrogen adsorbed in the pores also increase. The isothermal adsorption curve can be obtained by plotting the adsorbed nitrogen amount versus the relative pressure. After the relative pressure reaching the maximum, the nitrogen adsorbed on the surface of pores is desorbed with the decrease in relative pressure, and the curve of nitrogen desorption can be obtained.

The $\mathrm{N}_{2} \mathrm{GA}$ tests were carried out by using an automatic specific surface area $\&$ pore size analyzer produced by Quantachrome Instruments. The mass of the sample for $\mathrm{N}_{2} \mathrm{GA}$ tests varies between 4.5 and $8.1 \mathrm{~g}$. To remove the remaining bound water, capillary moisture, and volatile gases, all the samples were degassed in vacuum before $\mathrm{N}_{2} \mathrm{GA}$ tests, and the temperature was set at $110{ }^{\circ} \mathrm{C}$ for $8 \mathrm{~h}$. After that, the nitrogen with a purity greater than $99.999 \%$ was used to measure the amount of nitrogen adsorbed at different relative pressures ranging from 0.001 to 0.990 at the temperature of $77.3 \mathrm{~K}$.

The adsorption and desorption curves obtained from $\mathrm{N}_{2} \mathrm{GA}$ tests are shown in Fig. 1, and the calculated specific surface area, average pore diameter, and total pore volume are shown in Table 1. The specific surface area was calculated from BET method, and the total pore volume was calculated from BJH method. In general, the average pore diameter and total volume of sandstones are higher than those of shales.

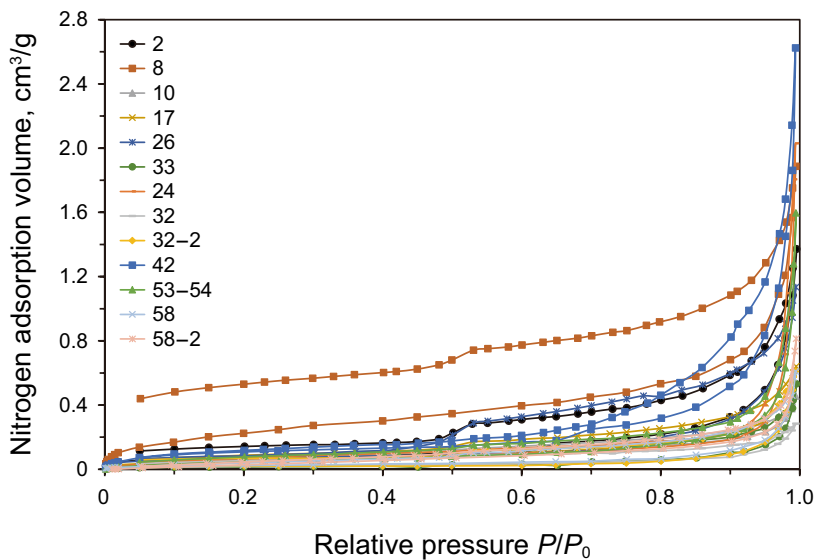

Fig. 1 The adsorption and desorption curves obtained from $\mathrm{N}_{2} \mathrm{GA}$ tests (Li et al. 2019)

\subsection{NMR}

NMR can obtain the pore size distribution in core without damaging core. NMR is based on the spin motion of the nucleus. In a specific magnetic field, the pore size distribution in the core is obtained by measuring the relaxation time of h-bearing fluid in different pores. In this paper, NMR $T_{2}$ spectrum of each core sample was measured using Oxford NMR instrument under $35^{\circ} \mathrm{C}$. Before measurement, the cores were cleaned, dried, vacuumed and saturated with bine. During the NMR measurement, $0.3 \mathrm{~ms}$ echo interval was adopted, and core samples were scanned with 64 times and 2048 echoes were obtained.

Three shale core samples and three tight sandstone pore samples were selected for NMR tests, and the obtained NMR $T_{2}$ spectra are shown in Fig. 2, and the measured porosity from NMR tests is shown in Table 2 . The porosity of shale samples varies from 0.7 to $1.3 \%$, and much lower than the porosity of three sandstone core samples, which varies from 4.7 to $7 \%$. The difference in porosity of shale and tight sandstone can be observed in $T_{2}$ spectra. The $T_{2}$ spectra of tight sandstone is mainly distributed between 0.1 and $100 \mathrm{~ms}$, but the range of $T_{2}$ spectra of shale is much narrower than the tight sandstone, which is mainly distributed between 0.1 and $3 \mathrm{~ms}$. Because the $T_{2}$ spectra distribution reflects the distribution of the pore size and can be converted into the pore radius (Yan et al. 2017). The relationship between relaxation time and core radius is exponential: $r=C T^{1 / n}$ (Wang et al. 2018; Xu et al. 2019). Xu et al. (2019) used HPMI and NMR experiments to obtain the conversion coefficient of pore radius and relaxation time of tight sandstone as $C=0.007$ and $n=0.725$. These parameters are used to convert the NMR spectra to the pore size distribution, as shown in Fig. 2. It can be found that shale pores are 
Table 1 Parameters obtained from $\mathrm{N}_{2} \mathrm{GA}$ tests ( $\mathrm{Li}$ et al. 2019)

\begin{tabular}{|c|c|c|c|c|c|}
\hline Core no. & Lithology & Depth & $\begin{array}{l}\text { Specific surface area, } \\
10^{-2} \mathrm{~m}^{2} / \mathrm{g}\end{array}$ & Average pore diameter, $\mathrm{nm}$ & $\begin{array}{l}\text { Total } \\
\text { volume, } \\
10^{-4} \mathrm{cc} / \mathrm{g}\end{array}$ \\
\hline 2 & Shale & 2069.88 & 28.3 & 30.06 & 21.58 \\
\hline 8 & Shale & 2070.77 & 89.88 & 13.02 & 27.18 \\
\hline 10 & Shale & 2071.08 & 22.22 & 12.72 & 6.81 \\
\hline 17 & Shale & 2071.98 & 20.22 & 19.66 & 9.69 \\
\hline 26 & Shale & 2073.18 & 24.24 & 29.03 & 17.50 \\
\hline 32 & Shale & 2074.19 & 7.474 & 23.56 & 4.36 \\
\hline 33 & Shale & 2074.19 & 5.175 & 63.80 & 8.92 \\
\hline 58 & Shale & 2050.09 & 8.572 & 44.06 & 9.42 \\
\hline $32-2$ & Shale & 2074.19 & 8.011 & 47.19 & 9.69 \\
\hline $58-2$ & Shale & 2050.9 & 20.36 & 24.76 & 12.61 \\
\hline $53-54$ & Sandstone & 2005.40 & 18.64 & 53.12 & 24.84 \\
\hline 42 & Sandstone & 2029.4 & 40.91 & 39.79 & 41.14 \\
\hline 24 & Sandstone & 2054.33 & 23.66 & 53.20 & 31.25 \\
\hline
\end{tabular}

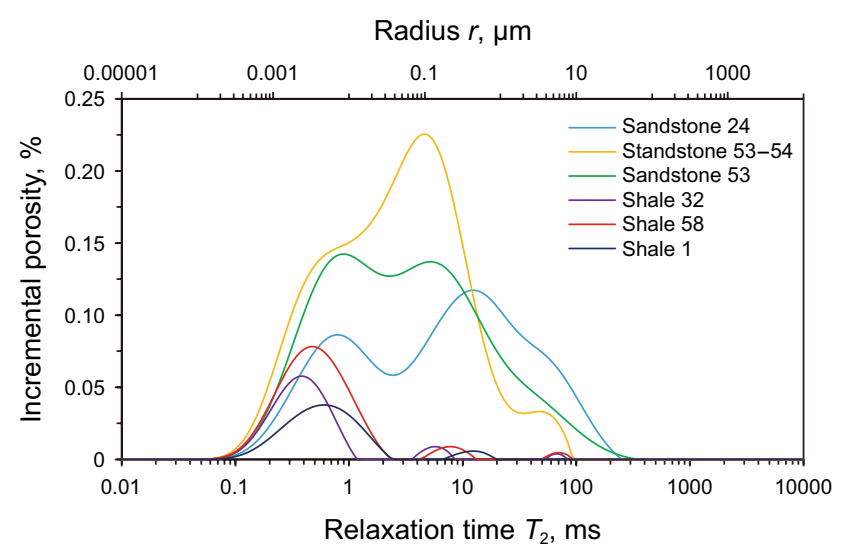

Fig. 2 NMR spectra and pore size distributions of shale and sandstone samples

mainly nanopores with the pore size ranging from $1 \mathrm{~nm}$ to $1 \mathrm{~mm}$, but there are a lot of micropores in sandstones, with the pore radius ranging from $1 \mathrm{~nm}$ to $10 \mathrm{~mm}$.

\section{Multifractal characteristics of pore structures with $\mathbf{N}_{\mathbf{2}} \mathbf{G A}$}

The multifractal spectra of pore structures are obtained by the above methods. In this paper, the parameter $q$ has a range of $[-10,10]$ and the interval of its value is 0.5 . The indirect method is used to obtain the generalized fractal dimension curve and the mass exponent curve of pore structures.

Based on adsorption curves of $\mathrm{N}_{2} \mathrm{GA}$ tests, the generalized fractal dimension spectra and mass exponent spectra obtained by the indirect method are shown in Fig. 3. It can be found that the $D_{q}-q$ graph (Fig. 3a) and $\tau_{q}-q$ graph (Fig. 3b) of each core samples are monotonous functions. With the increase of $q$, the generalized fractal dimension $D_{q}$ decrease and the mass exponent $\tau_{q}$ increases, indicating that the pore structures of shale and tight sandstone have multifractal characteristics.

The multifractal spectra of shale and tight sandstone pore structures obtained from $\mathrm{N}_{2} \mathrm{GA}$ are shown in Fig. 4, and the parameters of multifractal spectra obtained from $\mathrm{N}_{2} \mathrm{GA}$ curves are shown in Table 3. It can be found that the width of the multifractal spectra $\Delta \alpha(q)$ varies between 0.55 and 1.40 , and the cores 32 and 33 have the largest $\Delta \alpha(q)$, which is 1.40 , indicating that the spatial distributions in the cores 32 and 33 are the most complicated and the pore size

Table 2 The porosity measured from NMR tests

\begin{tabular}{lllllll}
\hline Core no. & 24 & $53-54$ & 53 & 32 & 58 & 1 \\
\hline Lithology & Sandstone & Sandstone & Sandstone & Shale & Shale \\
Porosity, $\%$ & 4.7 & 7 & 5.8 & 0.8 & 1.3 & 0.7 \\
\hline
\end{tabular}



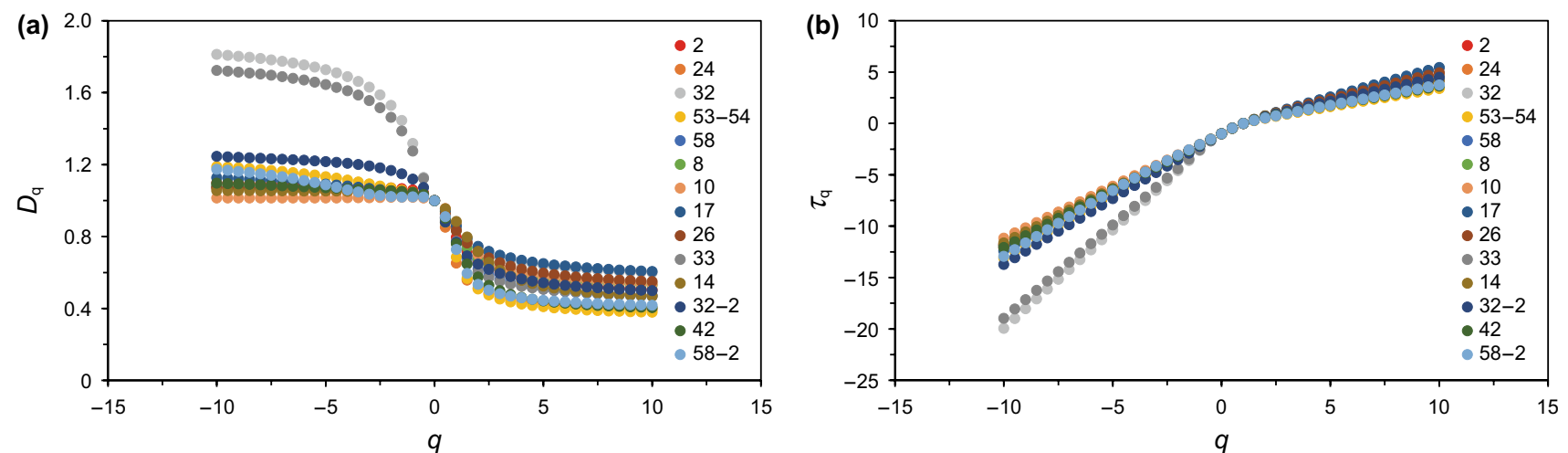

Fig. 3 Variation curve of generalized fractal dimension $D_{q}$ and mass exponent $\tau_{q}$ with index $q$ (a is the variation curve of generalized fractal dimension; $b$ is the variation curve of mass exponent)

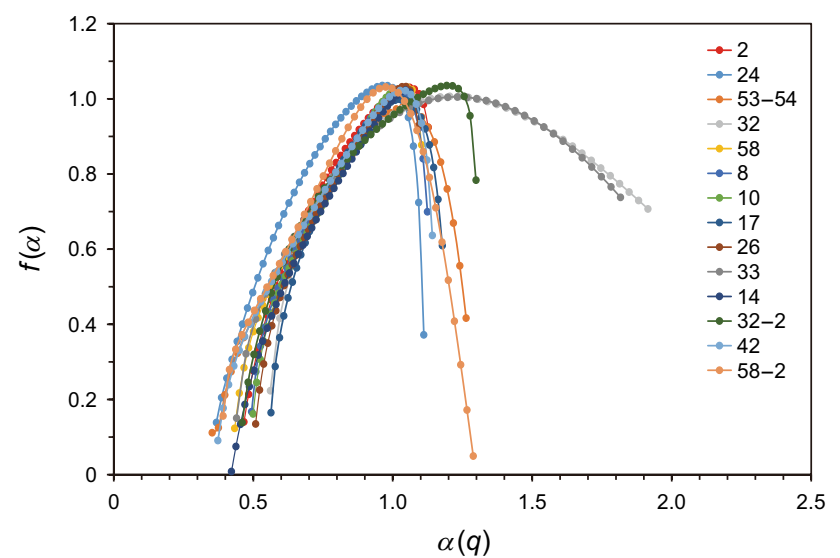

Fig. 4 Multifractal spectra of shale and tight sandstone pore structures obtained from $\mathrm{N}_{2} \mathrm{GA}$ concentration of the pore size distribution, and its value is between 1.01 and 1.22. The $\alpha_{0}(q)$ of core $32-2$ is 1.22 and is the maximum in all core samples, which means the fluctuation of pore size distribution of this core sample is largest. The deviation of the multifractal spectra $R_{d}$ is between -0.2 and 0.68 . The core 32 is shale and its value of $R_{d}$ is less than 0 , meaning the multifractal spectra are right-skewed, and the low-value information has a greater impact on multifractal spectra. Except the core 32, the multifractal spectra of the other core samples are all left-skewed, indicating the high-value information has a great influence on multifractal spectra. It can be found from the chart that the pore size distribution of the core 32 is the most complicated, but the core 10 which is shale has a small $\Delta \alpha(q)$ and $\alpha_{0}(q)$, indicating its pore size distribution is more concentrated and evenly distributed. Their pore size distributions measured by BJH method are shown in Fig. 5.

Table 3 Multifractal parameters calculated from $\mathrm{N}_{2} \mathrm{GA}$

\begin{tabular}{|c|c|c|c|c|c|c|c|}
\hline Core no. & $\Delta \alpha(q)$ & $f(\alpha)_{\max }$ & $f(\alpha)_{\min }$ & $\alpha_{0}(q)$ & $\alpha_{1}(q)$ & $\alpha_{2}(q)$ & $R_{d}$ \\
\hline 2 & 0.66 & 1.03 & 0.12 & 1.09 & 0.62 & 0.04 & 0.58 \\
\hline 8 & 0.63 & 1.01 & 0.17 & 1.06 & 0.57 & 0.06 & 0.50 \\
\hline 10 & 0.55 & 1.03 & 0.16 & 1.01 & 0.51 & 0.04 & 0.47 \\
\hline 17 & 0.61 & 1.00 & 0.18 & 1.08 & 0.51 & 0.10 & 0.42 \\
\hline 26 & 0.60 & 1.03 & 0.13 & 1.07 & 0.56 & 0.04 & 0.52 \\
\hline 32 & 1.40 & 1.00 & 0.22 & 1.16 & 0.60 & 0.80 & -0.20 \\
\hline 33 & 1.40 & 1.00 & 0.15 & 1.21 & 0.77 & 0.63 & 0.14 \\
\hline 58 & 0.68 & 1.02 & 0.12 & 1.07 & 0.63 & 0.05 & 0.58 \\
\hline $32-2$ & 0.84 & 1.00 & 0.10 & 1.22 & 0.76 & 0.08 & 0.68 \\
\hline $58-2$ & 0.90 & 1.02 & 0.03 & 1.02 & 0.63 & 0.27 & 0.36 \\
\hline $53-54$ & 0.91 & 1.01 & 0.11 & 1.09 & 0.74 & 0.18 & 0.56 \\
\hline 42 & 0.77 & 1.02 & 0.08 & 1.07 & 0.70 & 0.07 & 0.63 \\
\hline 24 & 0.78 & 1.03 & 0.12 & 1.04 & 0.68 & 0.10 & 0.57 \\
\hline
\end{tabular}

distributions are extremely uneven. The $\alpha_{0}(q)$ indicates the 


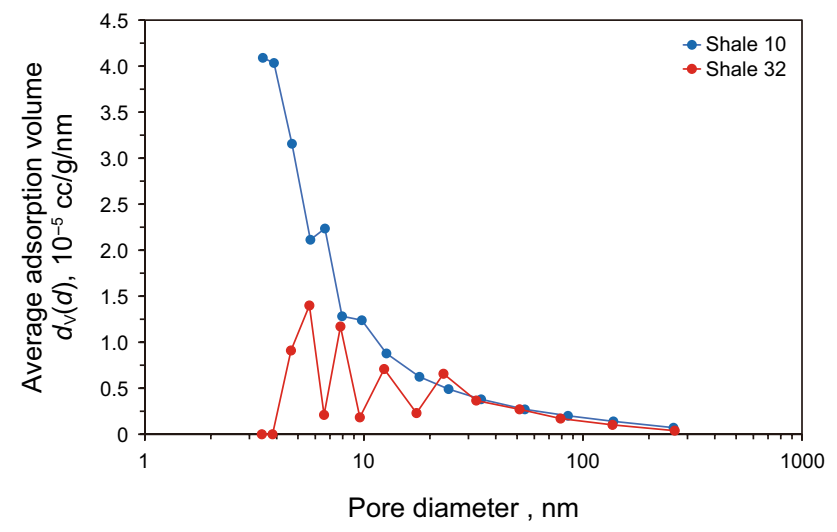

Fig. 5 Pore size distributions of the shale samples 10 and 32 obtained from $\mathrm{N}_{2} \mathrm{GA}$ tests

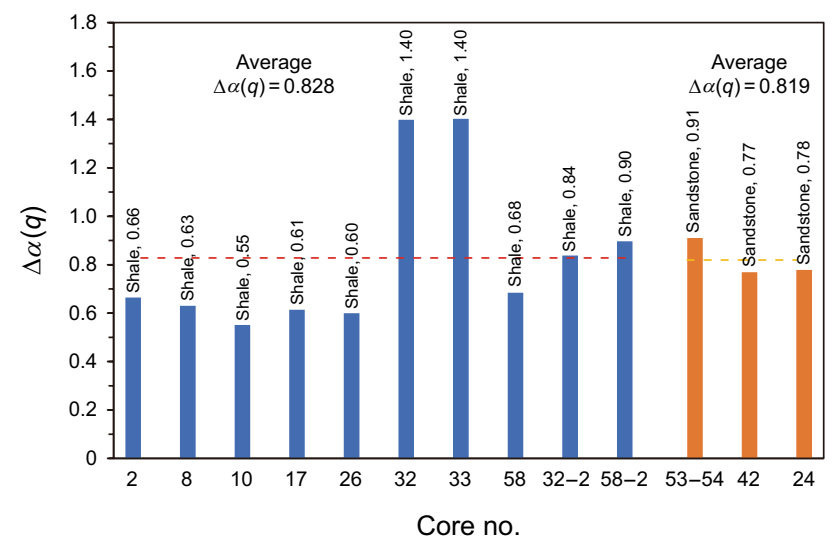

Fig. 6 Comparison of $\Delta \alpha$ between shale and sandstone core samples

As shown in Figs. 3 and 4, the mass exponent diagram and the multifractal spectra of shale 32 and shale 33 are significantly different from other core samples. When $q<0$, the generalized fractal dimension curve and mass exponent curve of these two core samples are clearly separated from other core samples. The $\Delta \alpha(q)$ values of the cores 32 and 33 are 1.40 , nearly twice the value of other core samples, as shown in Fig. 6. The higher the value of $\Delta \alpha(q)$ is, the more complex the pore size distribution inside the core sample will be, and the internal difference of the pore space will become greater. Therefore, the multifractal characteristics of cores 32 and 33 are discussed in detail. The study shows that the $\Delta \alpha(q)$ value decreases with the increase in the specific surface area. Corresponding to the higher values $\Delta \alpha$ of the cores 32 and 33, their specific surface areas are significantly smaller than other core samples. Comparing the specific surface area, total pore volume, and $R_{d}$ value of each core sample, it is found that the total pore volumes of cores 32 and 33 are the smallest, as shown in Fig. 7. Therefore,

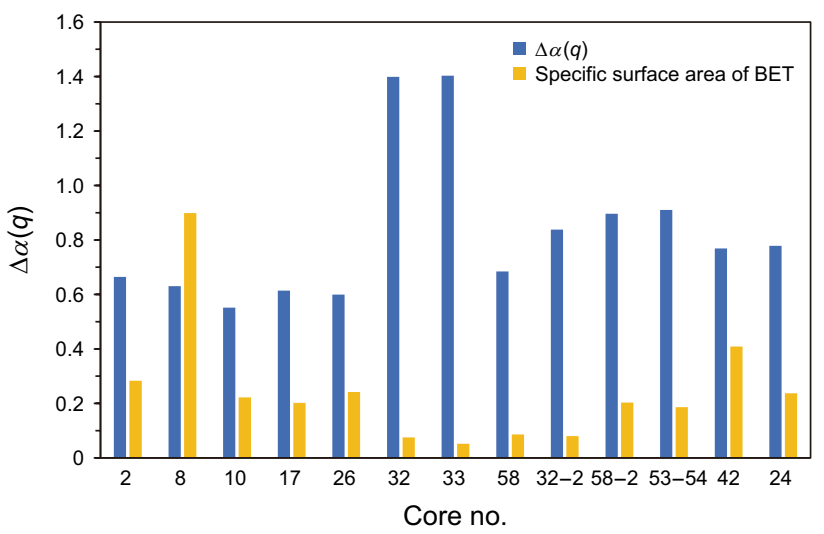

Fig. 7 Comparison of $\Delta \alpha$ value with the specific surface area measured from $\mathrm{N}_{2} \mathrm{GA}$ experiment

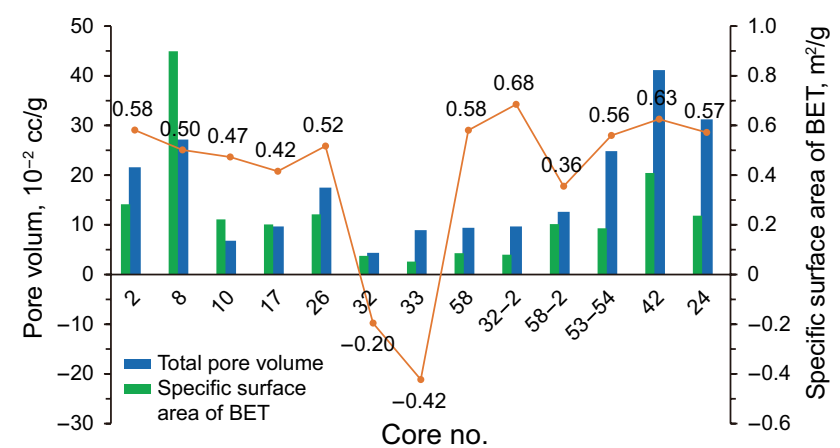

Fig. 8 Comparison of specific surface area, total pore volume and $R_{d}$

the values of $\Delta \alpha(q)$ have relations with the total pore volume and specific surface area.

Figure 8 shows the correlations between the specific surface area, total pore volume, and $R_{d}$. For shales, it is usually believed that the pores with the radius less than $2 \mathrm{~nm}$ are micropores, and the pores with the radius between 2 and $50 \mathrm{~nm}$ are mesopores, and the pores with the radius greater than $50 \mathrm{~nm}$ are macropores (Loucks et al. 2012). As the minimum pore radius measured by the $\mathrm{N}_{2} \mathrm{GA}$ experiment is about $3 \mathrm{~nm}$, the measured pores are mainly mesopores and macropores. Table 4 shows that the pores of the cores 32 and 33 are mainly mesopores, and their proportions of the large pores are low, $10 \%$ and $6 \%$, respectively. The $R_{d}$ values of the cores 32 and 33 are negative, indicating the low-value information of pore sizes has a great influence on multifractal spectra, which is consistent with the pore radius distribution. The $R_{d}$ values of the cores 58 and 32-2 are positive and large, indicating that the high-value information has great influence on multifractal spectra, and it is consistent with that their proportions of macropores are large, around $30 \%$. The proportions of macropores, $R_{d}$ values, and specific surface areas of all core samples are compared. It can be found 
Table 4 The proportion of macropores, $R_{d}$, and specific surface area of core samples

\begin{tabular}{llccl}
\hline Core type & Core no. & $R_{d}$ value & $\begin{array}{l}\text { Proportion } \\
\text { of macropo- } \\
\text { res, } \%\end{array}$ & $\begin{array}{l}\text { Specific } \\
\text { surface area, } \\
\mathrm{m}^{2} / \mathrm{g}\end{array}$ \\
\hline Cores with & 32 & -0.2 & 18.04 & 0.075 \\
small spe- & 33 & -0.42 & 5.4 & 0.052 \\
cific surface & 58 & 0.58 & 29.95 & 0.086 \\
area & $32-2$ & 0.68 & 31.94 & 0.08 \\
Cores with & 2 & 0.58 & 8.26 & 0.283 \\
small pro- & 8 & 0.5 & 5.01 & 0.899 \\
portion of & 10 & 0.47 & 3.23 & 0.222 \\
macropores & 17 & 0.42 & 5.95 & 0.202 \\
& 26 & 0.52 & 12.54 & 0.242 \\
& $58-2$ & 0.36 & 14.23 & 0.204 \\
\hline
\end{tabular}

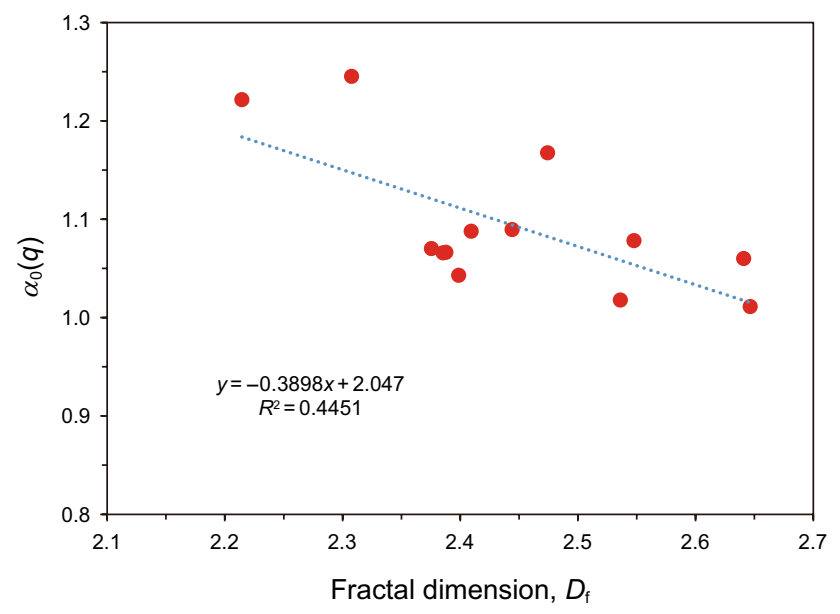

Fig. 9 The correlation between the fractal dimension calculated from FHH model and multifractal parameters $\alpha_{0}(q)$

that when the specific surface areas are similar, the larger the proportion of macropores is, the larger the $R_{d}$ value will be. When the proportion of macropores is small, $R_{d}$ value increases as the specific surface area increases.

The conventional fractal dimensions of these core samples have been calculated with Frenkel-Halsey-Hill (FHH) model based on $\mathrm{N}_{2} \mathrm{GA}$ ( $\mathrm{Li}$ et al. 2019). Comparing the fractal dimension with the parameters of multifractal characteristics, it is found that the fractal dimension calculated from FHH model has a negative linear correlation with $\alpha_{0}(q)$, as shown in Fig. 9. As $\alpha_{0}(q)$ reflects the fluctuation of pore size distributions, the larger the $\alpha_{0}(q)$ value is, the stronger the heterogeneity of pore size distribution is, and the proportion of macropores also increases.

Figure 10 shows the correlations between the multifractal parameters and the parameters of core samples calculated from $\mathrm{N}_{2} \mathrm{GA}$. It can be found that as the specific surface area increases, the width of the multifractal spectra $\Delta \alpha(q)$ (Fig. 10a), the maximum singularity index $\alpha_{0}(q)$ (Fig. 10b), and the width of the right side of the multifractal spectra $\alpha_{2}(q)$ (Fig. 10c) all decrease, which means the complexity of pore space distribution decreases, and the pore size distribution becomes more concentrated, and the influence of low-value information on the multifractal spectra decreases. As shown in Fig. 10d, the average pore radius has a good correlation with $\alpha_{1}(q)$. As the pore radius increases, $\alpha_{1}(q)$ increases, indicating the increase in the influence of the high-value information on multifractal spectra. Figure 10e shows that as the adsorption pore volume increases, $R_{d}$ increases logarithmically, and the influence of high-value information on multifractal spectra increases. Figure 10f depicts that the correlation between $\alpha_{2}(q)$ and adsorption pore volume is weak. As the adsorption pore volume increases, $\alpha_{2}(q)$ decreases logarithmically, and the influence of low-value information on multifractal spectra decreases.

\section{Multifractal characteristics of pore structures with NMR}

The multifractal spectra obtained using the NMR spectra are shown in Fig. 11. The parameters of the multifractal spectra are shown in Table 5. It can be seen that the multifractal spectra of the three plunger sandstones are right-skewed, and the $R_{d}$ value ranges from -0.42 to -0.09 , indicating the low-value information has a great influence on the multifractal spectra of NMR. As there are segmentations in NMR spectra of shale samples, the calculated multifractal spectra do not have obvious multifractal characteristics. The $R_{d}$ value of sandstone core 53 and other shale samples varies from -0.12 to 0.13 , and their multifractal spectra are closer to symmetrical bells.

Table 5 shows that the values of $\Delta \alpha(q), \alpha_{1}(q)$ and $\alpha_{2}(q)$ of sandstone are larger than those of shale. It means that compared with shale, tight sandstone has a wider pore size distribution, and more low-value information and high-value information. According to Liu et al.(2018), the clay mineral composition has a certain influence on the multifractal characteristics. As shown in Table 5, the mineral compositions of the tight sandstones and shales have been measured with X-ray diffraction analysis (XRD) and introduced in the previous study ( $\mathrm{Li}$ et al. 2019). It can be found that there are significant differences in the clay content and quartz content of shale and sandstone. The clay content for shales ranges from 24.8 to $35.0 \%$, while that of tight sandstones changes from 13.3 to $19.8 \%$. The shale quartz content is between 23.3 and $37.2 \%$, and less than that in sandstones, which varies between 60.9 and $61.3 \%$. The differences in clay content and quartz content lead to more small pores in shale, and 

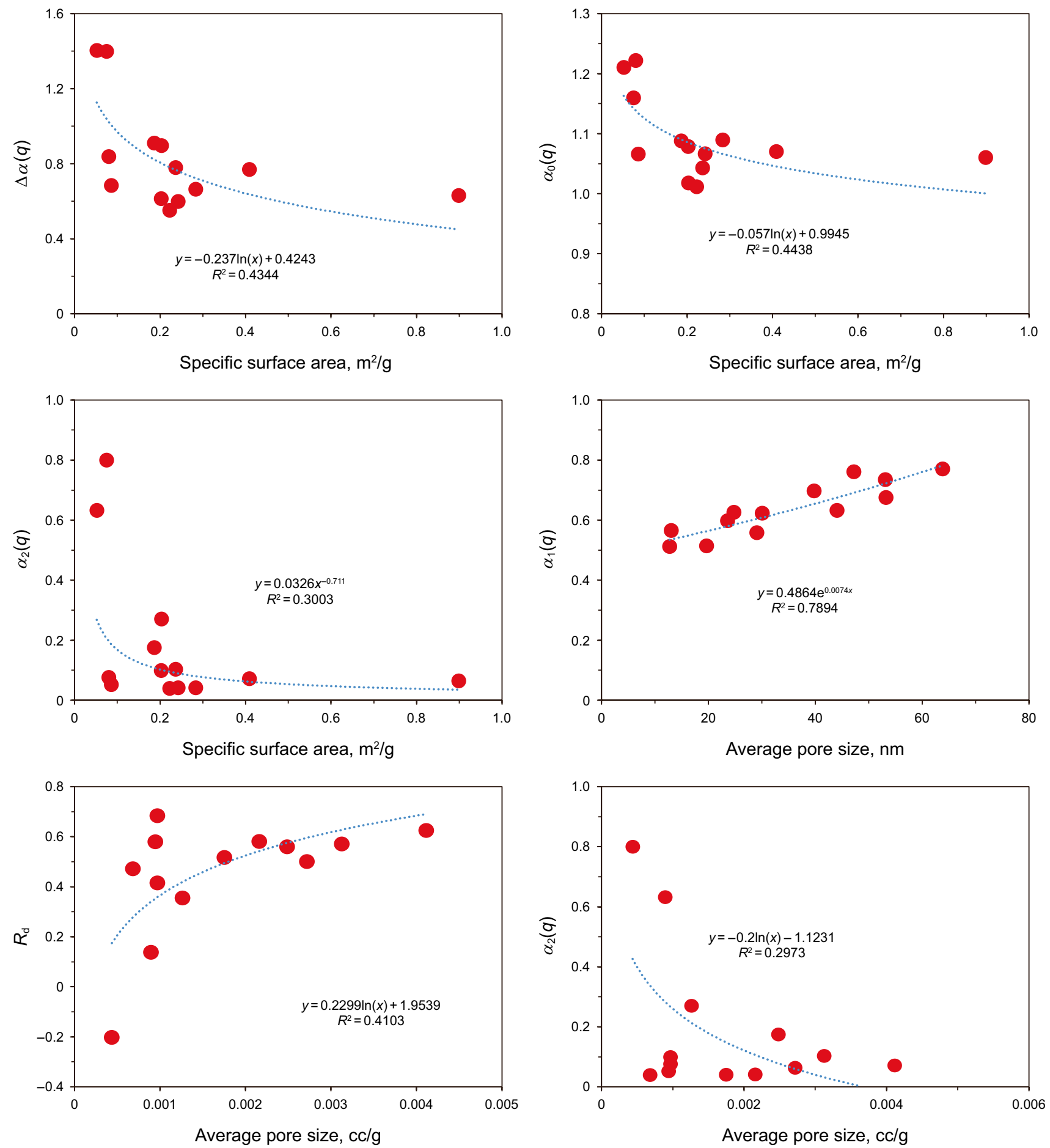

Fig. 10 Relationships between parameters of core samples and the multifractal parameters obtained by $\mathrm{N}_{2} \mathrm{GA}$ ( $\mathrm{a}, \mathrm{b}$, c is the relation curve between specific surface area and the width of the multifractal spectra $\Delta \alpha(q)$, the maximum singularity index $\alpha_{0}(q)$, and the width of the right side of the multifractal spectra $\alpha_{2}(q)$, respectively; d, e, f is the relation curve between average pore size and the width of the left-skewed of the multifractal spectra $\alpha_{1}(q)$, the value of $R_{d}$ and the width of the right-skewed of the multifractal spectra $\alpha_{2}(q)$, respectively)

some larger pores in sandstones. Therefore, the $\Delta \alpha$ value of tight sandstone is higher and its heterogeneity of pore size distribution is stronger.
Comparing NMR multifractal spectra and $\mathrm{N}_{2} \mathrm{GA}$ multifractal spectra of the sandstone cores 24 and 53-54, it can be found that the multifractal spectra obtained from NMR is wider than those of $\mathrm{N}_{2} \mathrm{GA}$, and the maximum singularity 


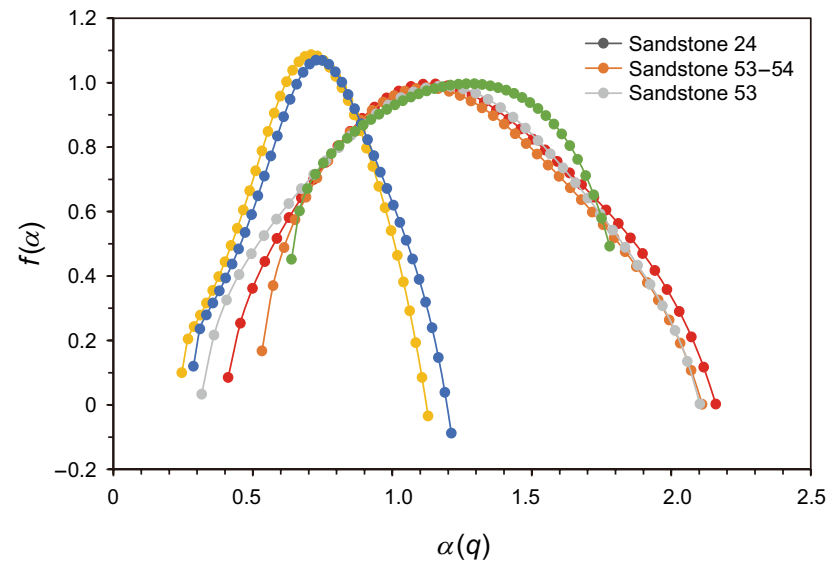

Fig. 11 The multifractal spectra calculated from NMR spectra

index of NMR multifractal spectra is larger, indicating that the pore size distribution obtained by NMR are more complicated and wider. The reason is that NMR can obtain the full-size distribution of pore sizes, from nanoscale pores to microscale pores. However, $\mathrm{N}_{2} \mathrm{GA}$ cannot characterize the microscale pores in tight sandstone, and the pore information obtained by $\mathrm{N}_{2} \mathrm{GA}$ only contains the nanoscale pores. In addition, the deviation direction of the NMR multifractal spectra is opposite to that of $\mathrm{N}_{2} \mathrm{GA}$ multifractal spectra. The NMR multifractal spectra are right-skewed, meaning the low-value information has a great influence on it, but the $\mathrm{N}_{2} \mathrm{GA}$ multifractal spectra are left-skewed, indicating it is more affected by high-value information.

\section{Conclusions}

The multifractal characteristics of shale and tight sandstone pore structures from the Chang 7 member of the Triassic Yanchang Formation in the Ordos Basin, NW China are studied with $\mathrm{N}_{2} \mathrm{GA}$ and NMR experiments. The following conclusions can be drawn:
- The multifractal parameters $\Delta \alpha(q)$ and $\alpha_{0}(q)$ can reflect the characteristics of pore size distributions in shale and tight sandstone, and can be used to characterize the complexity of pore size distribution. The increases of $\Delta \alpha(q)$ and $\alpha_{0}(q)$ indicate the pore size distributions of shale and tight sandstone become more complicated.

- The specific surface area and total pore volume of shale and tight sandstone are correlated with multifractal characteristics. When the specific surface area is similar, the larger the proportion of macropores is, the larger the $R_{d}$ value, and the greater the effect of high-value information on multifractal characteristics will be. For the core samples with the small proportion of macropores, the value of $R_{d}$ increases with the increase in the specific surface area.

- The specific surface area is negatively correlated with the width of the multifractal spectra $\Delta \alpha(q)$ and the maximum singularity index $\alpha_{0}(q) . \alpha_{1}(q)$ increases as pore size increases, and the influence of high-value information on the multifractal spectra increases. With the increase in total pore volume, $R_{d}$ increases logarithmically and the influence of the high-value information on multifractal spectra will increase.

- The multifractal parameters obtained from NMR and $\mathrm{N}_{2} \mathrm{GA}$ tests are different from each other. The values of $R_{d}$ measured from NMR spectra are negative, contrary to the results obtained from $\mathrm{N}_{2} \mathrm{GA}$ tests, which might be caused by the different pore size ranges characterized by these two different experiments. As tight sandstone usually has wider pore size distribution and higher porosity than shale, the values of $\Delta \alpha(q), \alpha_{1}(q)$ and $\alpha_{2}(q)$ of tight sandstone measured from NMR spectra are greater compared with those of shale.

Acknowledgements This work was supported by the National Natural Science Foundation of China (No. 51874320), and Scientific Research Foundation of China University of Petroleum, Beijing (No. 2462017BJB11).

Open Access This article is licensed under a Creative Commons Attribution 4.0 International License, which permits use, sharing, adaptation, distribution and reproduction in any medium or format, as long

Table 5 The multifractal parameters calculated from NMR spectra

\begin{tabular}{lllccrrr}
\hline Core no. & $\Delta \alpha(q)$ & $f(\alpha)_{\max }$ & $f(q) \min$ & $\alpha_{0}(q)$ & $\alpha_{1}(q)$ & $\alpha_{2}(q)$ & $R_{d}$ \\
\hline Sandstone 24 & 1.75 & 1.00 & 0.00 & 1.11 & 0.70 & 1.05 & -0.36 \\
Sandstone 53-54 & 1.58 & 1.00 & 0.00 & 1.11 & 0.58 & -0.42 \\
Sandstone 53 & 1.79 & 1.00 & 0.00 & 1.17 & 0.85 & 0.94 \\
Shale 32 & 1.06 & 1.09 & -0.04 & 0.74 & 0.49 & 0.57 \\
Shale 58 & 0.98 & 1.09 & -0.09 & 0.72 & 0.43 & -0.09 \\
Shale 1 & 1.14 & 1.00 & 0.45 & 1.28 & 0.64 & 0.55 \\
\hline
\end{tabular}


as you give appropriate credit to the original author(s) and the source, provide a link to the Creative Commons licence, and indicate if changes were made. The images or other third party material in this article are included in the article's Creative Commons licence, unless indicated otherwise in a credit line to the material. If material is not included in the article's Creative Commons licence and your intended use is not permitted by statutory regulation or exceeds the permitted use, you will need to obtain permission directly from the copyright holder. To view a copy of this licence, visit http://creativecommons.org/licenses/by/4.0/.

\section{References}

Chen L, Jiang ZX, Liu KY, et al. Quantitative characterization of micropore structure for organic-rich Lower Silurian shale in the Upper Yangtze Platform, South China: implications for shale gas adsorption capacity. Adv Geo-Energy Res. 2017;1(2):112-23. https://doi.org/10.26804/ager.2017.02.07.

Chhabra A, Roderick JV. Direct determination of the $\mathrm{f}(\alpha)$ singularity spectrum. Phys Rev Lett. 1989;62(12):1327-30. https://doi. org/10.1103/physrevlett.62.1327.

Cuevas E. $\mathrm{f}(\alpha)$ Multifractal spectrum at strong and weak disorder. Phys Rev B. 2003;68(2):1-6. https://doi.org/10.1103/physr evb.68.024206v.

Du SH, Shi YM. Rapid determination of complete distribution of pore and throat in tight oil sandstone of Triassic Yanchang Formation in Ordos Basin, China. Acta Geologica Sinica English Edition. 2019;3:1-13. https://doi.org/10.1111/1755-6724.13881.

Er C, Zhao JZ, Yao JL, et al. Characterization of pores and fracture networks in organic-rich shale and tight sandstone of the Chang-7 member, Triassic Yanchang Formation, Ordos Basin. Oil Gas Geol. 2016;37(2):341-53. https://doi.org/10.11743/ogg2016030 6 (in Chinese).

Falconer K. Fractal geometry: mathematical foundations and applications. Hoboken: Wiley; 2004.

Ferreiro JP, Miranda JGV, Vázquez EV. Mul fractal analysis of soil porosity based on mercury injec on and nitrogen adsorp on. Vadose Zone J. 2010;2(9):325-35. https://doi.org/10.2136/vzj20 09.0090 .

Ferreiro JP, Wilson M, Vázquez EV. Multifractal description of nitrogen adsorption isotherms. Vadose Zone J. 2009;8(1):209-20. https ://doi.org/10.2136/vzj2008.0007.

Ge XM, Fan YR, Zhu XJ, et al. Determination of nuclear magnetic resonance T2 cutoff value based on multifractal theory-an application in sandstone with complex pore structure. Geophysics. 2015;80(1):D11-21. https://doi.org/10.1190/geo2014-0140.1.

Halsey TC, Jensen MH, Kadanoff LP, Procaccia I, Shraiman BI. Fractal measures and their singularities: the characterization of strange sets. Nucl Phys B ProcSuppl. 1986;33(2):501-11. https://doi. org/10.1201/9780203734636-46.

$\mathrm{Hu} \mathrm{QH}$, Zhang YX, Meng XH, et al. Characterization of micro-nano pore networks in shale oil reservoirs of Paleogene Shahejie Formation in Dongying Sag of Bohai Bay Basin, East China. Pet Explor Develop. 2017;44(5):720-30. https://doi.org/10.1016/ s1876-3804(17)30083-6.

Jiang ZC, Mao ZQ, Shi YJ, et al. Multifractal characteristics and classification of tight sandstone reservoirs: a case study from the triassic Yanchang formation, Ordos Basin, China. Energies. 2018;11(9):1-17. https://doi.org/10.3390/en11092242.

Jouini MS, Vega S, Mokhtar EA. Multiscale characterization of pore spaces using multifractals analysis of scanning electronic microscopy images of carbonates. Nonlinear Process Geophys. 2011;18(6):941-53. https://doi.org/10.5194/npg-18-941-2011.

Ju W, You Y, Chen YL, et al. Nanoscale pore structure and fractal characteristics of the continental Yanchang Formation Chang 7 shale in the southwestern Ordos Basin, central China. Energy Sci Eng. 2019;7(4):1188-200. https://doi.org/10.1002/ese3.339.

Lai J, Wang GW, Cao JT, et al. Investigation of pore structure and petrophysical property in tight sandstones. Mar Pet Geol. 2018;91:17989. https://doi.org/10.1016/j.marpetgeo.2017.12.024.

Lai J, Wang GW, Fan ZY, et al. Insight into the pore structure of tight sandstones using NMR and HPMI measurements. Energy Fuels. 2016;30(12):10200-14. https://doi.org/10.1021/acs.energyfuel s.6b01982.

Li H, Zhang ZQ, Shi YM. New characterization on the petrophysical characteristics of tight sandstone reservoirs in Yanchang Formation Ordos Basin China. Energy Explor Exploit. 2016;34(6):84464. https://doi.org/10.1177/0144598716665038.

$\mathrm{Li} \mathrm{P}$, Zheng M, Bi H, et al. Pore throat structure and fractal characteristics of tight oil sandstone: a case study in the Ordos Basin, China. J Petrol Sci Eng. 2017;149:665-74. https://doi.org/10.1016/j.petro 1.2016.11.015.

Li XH, Gao ZY, Fang SY, et al. Fractal characterization of nanopore structure in shale, tight sandstone and mudstone from the ordos basin of China Using Nitrogen adsorption. Energies. 2019;12(4):1-11. https://doi.org/10.3390/en12040583.

Liu KQ, Ostadhassan M. The impact of pore size distribution data presentation format on pore structure interpretation of shales. Adv Geo-Energy Res. 2019;3(2):187-97. https://doi.org/10.26804/ ager.2019.02.08.

Liu M, Xie RH, Guo JF, et al. Characterization of pore structures of tight sandstone reservoirs by multifractal analysis of the NMR $\mathrm{T}_{2}$ distribution. Energy Fuels. 2018;32(12):12218-30. https://doi. org/10.1021/acs.energyfuels.8b02869.

Lopes R, Betrouni N. Fractal and multifractal analysis: a review. Med Image Anal. 2009;13(4):634-49. https://doi.org/10.1016/j.media .2009.05.003.

Loucks RG, Reed RM, Ruppel SC, Hammes U. Spectrum of pore types and networks in mudrocks and a descriptive classification for matrix-related mudrock pores. AAPG Bull. 2012;96(6):1071-98. https://doi.org/10.1306/08171111061.

Lyu C, Cheng QM, Zuo RG, et al. Mapping spatial distribution characteristics of lineaments extracted from remote sensing image using fractal and multifractal models[J]. J Earth Sci. 2017;028(003):507-15. https://doi.org/10.1007/s1258 3-016-0914-x.

Mandelbrot BB. The fractal geometry of nature. New York: WH Freeman; 1983. p. 173.

Meakin P. Fractal structures. Prog Solid State Chem. 1990;20(3):135233. https://doi.org/10.1016/0079-6786(90)90001-V.

Peng RD, Yang YC, Ju Y, et al. Computation of fractal dimension of rock pores based on gray CT images. Chin Sci Bull. 2011;56(31):3346-57. https://doi.org/10.1007/s1143 4-011-4683-9.

Posadas A, Quiroz R, Tannús A, et al. Characterizing water fingering phenomena in soils using magnetic resonance imaging and multifractal theory. Nonlinear Process Geophys. 2009;16(1):159-68. https://doi.org/10.5194/npg-16-159-2009.

Rényi A. On a new axiomatic theory of probability. Acta Math Hungarica. 1955;6(3-4):285-335.

Shao XH, Pang XQ, Li QW, et al. Pore structure and fractal characteristics of organic-rich shales: a case study of the lower Silurian Longmaxi shales in the Sichuan Basin, SW China. Marine Petrol Geol. 2017;80:192-202. https://doi.org/10.1016/j.marpe tgeo.2016.11.025

Singh H. A critical review of water uptake by shales. J Nat Gas Sci Eng. 2016;34:751-66. https://doi.org/10.1016/j.jngse.2016.07.003.

Singh H, Cai JC. A mechanistic model for multi-scale sorption dynamics in shale. Fuel. 2018;234:996-1014. https://doi.org/10.1016/j. fuel.2018.07.104. 
Vázquez EV, Ferreiro JP, Miranda JGV, et al. Multifractal analysis of pore size distributions as affected by simulated rainfall. Vadose Zone J. 2008;7(2):500-11. https://doi.org/10.2136/vzj2007.0011.

Wang FY, Jiao L, Lian PQ, et al. Apparent gas permeability, intrinsic permeability and liquid permeability of fractal porous media: carbonate rock study with experiments and mathematical modelling. J Petrol Sci Eng. 2019;173:1304-15. https://doi.org/10.1016/j. petrol.2018.10.095.

Wang FY, Yang K, Cai JC. Fractal characterization of tight oil reservoir pore structure using nuclear magnetic resonance and mercury intrusion porosimetry. Fractals. 2018;26(02):1-11. https:// doi.org/10.1142/s0218348x18400170.

Wang WR, Yue DL, Eriksson KA, et al. Quantification and prediction of pore structures in tight oil reservoirs based on multifractal dimensions from integrated pressure- and rate-controlled porosimetry for the upper Triassic Yanchang formation, Ordos Basin, China. Energy Fuels. 2020;34(4):4366-83. https://doi. org/10.1021/acs.energyfuels.0c00178.

Xie SY, Cheng QM, Ling QC, et al. Fractal and multifractal analysis of carbonate pore-scale digital images of petroleum reservoirs. Mar Pet Geol. 2010;27(2):476-85. https://doi.org/10.1016/j.marpe tgeo.2009.10.010.

Xu HJ, Fan YR, Hu FL, et al. Characterization of pore throat size distribution in tight sandstones with nuclear magnetic resonance and high-pressure mercury intrusion. Energies. 2019;12(8):1-17. https://doi.org/10.3390/en12081528.

Yan JP, He X, Geng B, et al. Nuclear magnetic resonance T2 spectrum: multifractal characteristics and pore structure evaluation.
Appl Geophys. 2017;14(2):205-15. https://doi.org/10.1007/s1177 0-017-0614-0.

Yang H, Niu XB, Xu LM, et al. Exploration potential of shale oil in Chang7 member, upper Triassic Yanchang formation, Ordos Basin, NW China. Petrol Explor Develop. 2016;43(4):560-9. https://doi.org/10.1016/s1876-3804(16)30066-0.

Yang WL, Li XY, Xu Z, et al. Shale oil resources assessment for the member Chang 7 in Ansai area of ordos Basion. Marine Geol Front. 2019a;35(4):48-56. https://doi.org/10.16028/j.10092722.2019.04006 (in Chinese).

Yang YF, Yang HY, Tao L, et al. Microscopic determination of remaining oil distribution in sandstones with different permeability scales using computed tomography scanning. J Energy Resour Technol. 2019b;141(9):1-11. https://doi.org/10.1115/1.4043131.

Yin XD, Jiang S, Chen SJ, et al. Impact of rock type on the pore structures and physical properties within a tight sandstone reservoir in the Ordos Basin, NW China[J]. Petrol Sci. 2020. https://doi. org/10.1007/s12182-020-00460-y.

Yu S, Bo J, Pei S, et al. Matrix compression and multifractal characterization for tectonically deformed coals by $\mathrm{Hg}$ porosimetry. Fuel. 2018;211:661-75. https://doi.org/10.1016/j.fuel.2017.09.070.

Zhao PQ, Wang L, Xu CH, et al. Nuclear magnetic resonance surface relaxivity and its advanced application in calculating pore size distributions. Mar Petrol Geol. 2020;111:66-74. https://doi. org/10.1016/j.marpetgeo.2019.08.002.

Zhu L, Jin ND, Gao ZK, et al. Multifractal analysis of inclined oilwater countercurrent flow[J]. Petrol Sci. 2014;11:111-21. https ://doi.org/10.1007/s12182-014-0322-9. 